\title{
ZARATA DA GARAIPENA? KAPITALISMO BIZKORTUA ETA BERE SOINU BANDA(K)
}

\section{Ion Andoni del Amo Castro}

Universidad del País Vasco / Euskal Herriko Unibertsitatea. Dpto. Sociología II / Soziologia II Saila NOR Ikerketa Taldea

\section{Arkaitz Letamendia Onzain}

Universidad del País Vasco / Euskal Herriko Unibertsitatea. Dpto. Sociología II / Soziologia II Saila; Dpto. Sociología y Trabajo Social / Soziologia eta Gizarte Langintza Saila PARTE HARTUZ Ikerketa Taldea

\section{Laburpena}

Modernitatearen helburua artelan totalak garatzea zen, bere garaiaren esentzia antzematen zutenak. Beethovenen "Sinfonia Heroiko" artelan musikala dugu honen adibide: soinu totala. Bestetik, XX. mendearen hasieran italiar futuristak zarataren artearen etorrera sumatzen hasi ziren; hiriko eta industria paisaiaren abiadura, energia eta zarata aldarrikatuz. Kapitalaren errotazio abiaduraren bizkortzearekin batera, musikaren erritmoa ere azeleratu egin da. Musika industrialak, elektronikoak eta punkak bere garaiko zarata (eta abiadura) hartzen dute oinarri. Zarata hauek soinu izan nahi dute, garaiko inkomunikazioa bada ere komunikatzen dutena: zarataren soinua. Egungo kapitalismo azeleratuak denbora historikoaren zatiketa dakar, logika postmodernoaren bitartez produktu kulturalen hustuketa sustatuz. Musikan diskoaren narratibaren aurrean zatiketa nagusituz doa; abesti solteak, bere testuinguru orokorretik erauziak. Deskonexioa ultra konexioaren garaian: zarata totala.

\section{MEANS NOISE A VICTORY? ACCELERATED CAPITALISM AND ITS SOUNDTRACK(S)}

\section{Abstract}

The goal of the modernity was to develop total artworks, able to reflect the essence of their time. Beethoven's "Eroica" could be considered as an example of it: Total Sound. At the beginning of the $20^{\text {th }}$ century Italian futurists perceived the arrival of the Art of the Noise; they claimed for the velocity, the energy and the noise of the city and the industrial landscape. Together with the acceleration of the rotation of the Capital, the rhythm of the music itself also gets accelerated. Industrial, electronic and punk musics express the noise (and the velocity) of their own time. But this noise wants to become sound, even if it is the lack of communication what it wants to communicate: the Sound of the Noise. Today's accelerated capitalism results in the fragmentation of the historical time, and together with its postmodern logic, the cultural products get empty. The musical narrative of the full disc splits up: isolated songs emerge, away from their own context. Disconnection in the ultra connection era: Total Noise.

Key words: MUSIC; NOISE; SOUND; POSTMODERNISM; ACCELERATION

\footnotetext{
Del Amo Castro, Ion Andoni \& Arkaitz Letamendia Onzain. 2015. "Zarata da garaipena? : Kapitalismo bizkortua eta bere soinu banda(k)". AusArt 3 (2): 173-187. DOI: 10.1387/ausart.15954
}

\section{AUSART}




\section{MODERNITATEAREN ESENTZIA ETA SOINU TOTALA}

1. Premisa: Artelan totala, bere aro historikoaren esentzia harrapatzen duen artelana; bere garaiaren ezaugarri sakon eta definitzaileak islatzen duen lan artistikoa. Ze nolako soinuak azaleratu daitezke premisa honen inguruan?

Premisa hau garatzeko, lehenik eta behin esentziaren kontzeptualizazioan sakondu beharko da; ba al da esentziarik gure mundu garaikidean? Baldin badago, zeintzuk dira bere ezaugarri nagusiak, artelan espezifikoetan islatu daitezkeenak? Ideia hau garatzeko, har dezagun Europan sortutako mundu modernoaren konfigurazioa abiapuntu bezala. XVIII. mendearen amaieratik aurrera, kapitalismo industriala eta estatu nazionalaren arteko konbinazioan sortutako munduak esentzia bereizgarri eta iraultzaile bat erditu zuen (Bergeron, Furet, Koselleck 1969). Estrukturazio guztiz berritua, gizartea politikoki eta sozioekonomikoki antolatzeko modu iraultzailea. Mundu berri baten erditzeak, gizarte berri baten jaiotzak, artelan total eta hortaz musikaltasun total, berezi eta bereizgarria islatu dezake: soinu totala.

Jean Paul Sartreren esanetan, esentziaren aurretik ekintza askatzailea dago, gizakion existentzia definitzen duen ekintza hain zuzen; ekintza aktiboa da beraz esentzia definitzen duena (Morey 2015). Hortaz, ontologikoki askatasunari lotuta gaude gizakiok, nahiz eta bizitzan zehar, praktikan, askatasun hau ez den eremu askotan gauzatzen. Talde soziokultural eta herriei aplikatuta, subjektu aktibo baten ekintza askatzailea ere izan beharko da esentzia eraberritua erditu dezakeen agentea; zentzu honetan, frantsesaren moduko iraultza politikoa esentzia kolektibo, historiko bereizgarri batekin lotu daiteke; esentzia totala erdituko duen gertaera, agentzia popular askatzaile batek ahalbidetuta. Gertakizun iraultzaile honen soinuak egoeraren handitasunaren parekoak izan beharko dira. Gertaera historiko totalak artelan musikala totala ahalbidetuko du, esentzia eraberritu (kasu honetan moderno) baten baitan.

Hortaz planteatu daiteke Iraultza Frantsesak (ekintza kolektibo totala) moldatu eta gorpuztu zuela mundu moderno eta esentzia historiko berri honen jaiotzea. Botere aristokratiko tradizionalei herriaren subiranotasunaren ideia nagusituko zaio; jabekuntza gizarteko sektore ezberdinei zabaltzeko grina hain zuzen; botere eratzaile bilakatuz. Nazioaren ideia, bere mesianismo politiko puntuarekin batera, klase sozial ezberdinak estatu berrituaren proiektu eraldatzailean barneratzen saiatuko da (Bergeron, Furet, Koselleck 1969). Idealki proiektu eraldatzaile, iraultzaile, heroiko baten aurrean gaude; pertsonai 
eta artelan heroikoak eratzen dituen esentzia historiko totala. Bere neurriko adierazpen artistiko total baten adibidetzat, musika himno bereizgarria, Beethovenen 3. Sinfonia hartuko dugu'; Sinfonia Heroikoak hain zuzen, 1806 urtean argitaratuta, esentzia total eta eremu historiko honen musikaltasuna adieraziko duena; soinu totalaren gauzatzea.

Napoleonen omeneko titulua hartu zuen sinfoniak lehen momentu batean; indibiduo askatzaile eta iraultzailearen eredu idealizatua, heroiaren esentzia pertsonifikatuta (pertsonai historiko totala). Hortik gutxira Napoleon, bere irrika espantsionista eta militaristarekin batera, tirano inperialista bilakatuko da Europako hainbeste herri eta pertsonentzat. Beethoven laster konturako da bilakaera honetaz, Napoleonen izena sutsuki ezabatuz sinfoniaren titulutik²; baina pertsonai heroikoaren ideala eta epikotasuna musikaren tonalitatean antzemango da; espiritu eta esentzia berri batek dakarren soinu osoa, totala.

Gizakiokin bezala, badirudi historia modernoaren bilakaeran ere askatasuna ez dela gauzatuko, garai historiko iraultzaile baten erroak ustelduko diren heinean. Adorno eta Horkheimerek esanetan, esentzia modernoan errotutako Ilustrazioaren proiektu askatzaileak tirania eta alienazio masibora eraman gaitzake; garaiaren esentzia islatzen eta kritikatzen ez duten espresio artistikoez osatutako garaia hain zuzen, masa industria kulturalarekin gertatuko den bezala (Adorno eta Horkeimer 1994). Emantzipazio indibidual eta popularraren beste muturrean kokatzen den esentzia total bereizgarri bat inposatu daiteke alienazio kontsumista masiboaren egoera honetan: faxismoak eskaintzen duena.

Beethovenen kasuan, mundu iraultzaile eta modernoaren hastapenetan erditutako esentziak melodia sakona, heroikoa ahalbidetuko du (artelan totala). Perspektiba honetan, Sinfonia Heroikoaren baitan kokatzen den erromantizismo musikalaren jaiotzea, erditze historiko total baten korrelazio artistikotzat har daiteke. Garai horretako munduan zeuden errealitate saihestezinak, soilik emozio, sentimendu eta intuizioen bitartez antzemango dira; eta erromantizismoko musika emozio haiek islatzen saiatuko da. Arte modernoarekin gertatuko den bezala, helburua eternoa irudikatzea izango da; denbora eta bere nolakotasun iheskorrak antzematea (Harvey 1998). Garai iraultzaile baten bilakaera musikaltasun emozional total, sinfonia oso eta indartsuaren bitartez adieraziko da; aro berri baten etorrera iragartzen duen soinu eta espresio artistiko osoa hain zuzen. Emozio sakon eta zirraragarria; garai eta esentzia berri eta total baten aurrean sortarazten den zirrara. 
Sinfonia Heroikoan islatuko da soinu total hau, erritmo geldo eta progresibo baten baitan bilakatuta (erritmo eta esentzia heroikoa). Momentuz Walter Benjaminek adieraziko duen erreprodukzio teknikoen aurretiko garaian gaude. Pieza musikal osoak eragiten dituen garaia da Beethovenena; parte txikiagoetan ez zatitutako eta zuzenean joko den soinu geldo eta osoaren domeinua. Obra korala; existentzia singularra, "hemen eta oraina" adierazten duen artelan musikal auratikoaren aroan gaude oraindik; teknikoki erreproduzitu ezin daitekeena (Benjamin 1989). XX. mendean zehar, teknika industrialak sartzean musikaren munduan, pieza musikalen erritmo progresibo eta geldoa poliki azkartzen joango da; eta obra osoa pieza laburragoetan zatitzen joango da (Negus 1996). Musika progresiboki, kapitalismo azkartuaren etorrerarekin batera, zarata industrializatuak ahalbidetzen duen abiadura azeleratua (gizakiak berez hartu ezin duena) eta konfigurazio zatikatua hartzen joango da.

Soinu totalarekin lotzen den erritmo geldo eta tonalitate heroikoa ahulduko da egoera honetan. Bestetik, XX. mendea aurrera joan ahala, Mendebaldean subjektu iraultzailea ez da argiki gorpuztuko, eta hortaz ekintza aktiboari dagokion esentziaren ideia ere lausotuko da. Aurrez aurre kontrajarrita, pertsona eta herri aske eta aktiboen eredua alde batean (esentzia total berritua definitu dezakeena); eta beste aldean masa alienatu eta pasiboaren errealitatea aurkituko ditugu, bakarrik kontsumitzeko aske bilakatzen den herri otzana (Adorno eta Horkheimer 1994). Honekin batera, modernitatearen aurrerapenaren ideala ere zaurituta geldituko da. Artelan totala - lan artistiko sakona, kritikoa, osoa, garaiaren erroetara doana, egoera historikoaren (auto) hausnarketa eta munduan pertsonen posizioari buruzko gogoeta indibidual eta kolektiboaren adierazlea- nekez iraungo dio etortzekoak diren hondamendiei .

I. Gerra Mundialarekin batera etorriko diren triskantzekin batera, XX. mendean zehar ideal modernoen goranzko eboluzio lineala apurtuko da, eta honek ondorio zuzenak izango ditu espresio artistikoetan (Hobsbawm 2003). Hala nola, musikaren tonalitate heroiko eta erritmo geldo, pausatu, progresibo, osoek (Sinfonia Heroikoaren ereduan gorpuzten zirenak) ez dute bizirauteko paradarik izango etorkizunak dakarren mundu zauritu, zatikatu eta azkartuan. Ideal modernoaren baitan zarata industrial azeleratuaren eredua etortzekoa da; italiar futuristek antzemango duten eta espresiboki erabiliko dituzten ezaugarri bereizgarriekin. Kapitalaren errotazioaren azelerazioarekin lotutako sakontasun espresibo gabeko gainazaleko anti-esentzia etortzekoa da; denbora sozial orokorraren azkartze eta zatikatzearekin batera agertuko den konfigurazioa eta, ondorioz, inpaktu zuzena izango duena artelan artistiko eta musikaren espresibotasunean. Testuinguru honetan, ba al da hitzegiterik 
XX. mendean esentzia bereizgarri batez; hain azkarra den denbora sozial batean non etengabe gertatzen diren aldaketak apenas digeritu daitezkeen, norbanakoen esperientzia sentsorial eta auto-kontzienteak gainezka egiten duten garai batean? Artelan totalak (soinu totalak) ekoiztu daitezke eszenario honetan? Gogoeta eta zalantza hauek gure proposamenaren bigarren premisara garamatzate.

\section{ZARATAREN SOINUA}

Los teóricos del totalitarismo han propugnado la necesidad de prohibir el ruido subversivo porque enfatiza las demandas de autonomía cultural y promueve las diferencias; el interés por mantener el tonalismo, la primacía de la melodía y la desconfianza en los nuevos lenguajes, códigos e instrumentos, es común a todos los regímenes de esta naturaleza.

(Leónidas Martín Saura 2006, 18)

2. Premisa: Soinu totalak, esentzia total (ekintza total iraultzailea) gorpuzten ez duen garai batean inposatzen bada (XX. mendeko mendebaldea), totalitarismora eraman gaitzake. Modernitate progresibo eta linealaren kritika eta hausturarekin batera, armonia zarata bilakatzen da. Kapitalismoaren azelerazioak zarataren soinua (artelan zatikatua) dakar, bere garaiko kontraesanak adierazi dezakeen espresibotasunarekin. Gure hitzak ere, azeleratu egiten zaizkigu.

Modernitateak berak zekarren jatorrizko kontraesan bat bere baitan, kultura popularraren lekua:

La ilustración piensa que este pueblo al que hay que recurrir para legitimar un gobierno secular y democrático es también el portador de lo que la razón quiere abolir: la superstición, la ignorancia y la turbulencia. Por eso, se desarrolla un dispositivo complejo, en palabras de Martín Barbero, 'de inclusión abstracta y de exclusión concreta'. El pueblo interesa como legitimador de la hegemonía 
burguesa, pero molesta como lugar de lo in-culto por todo lo que le falta.

(García Canclini 2001, 197)

Jasoa eta popularra. Modernitateak dikotomia hori instalatu zuen. Kultura jasoa da kulturatzat jotzen den bakarra, kultura zilegia. Kultura, klase bereizketa nabarmentzeko lekua zen. Europan bereziki, mekanismo hori luzaro mantendu da (Bourdieu 1999). Musikagintzan, musika klasikoa eta tonalitatea ziren musika jasoaren paradigma.

Erromantikoak, egia esan, berehala jabetu ziren. Kontraesan horri eutsi eta saiatu ziren uztartzen: politika eta egunerokoa, kultura eta bizitza (García Canclini 2001). Kultura eta musika popularrak berreskuratu zituzten. XIX. mendean: Fréderic Chopinek eta Franz Listzek musika popularrekiko interesa adierazi zuten. Jarrera XX. mendean areagotu egin zen: Debussy eta musika balinesa, Manuel de Falla iberiar folklorearen lurpean murgilduta, Igor Stravinski eslaviar errituen muinean sartu eta musika klasikora eraman, Béla Bartókek Hungariako plaza, kale edo elizetan festako herri-doinuak bildu... (Kyrou 2006). Saiakera honetan bertan, aldiz, kultura popularra bahituta gertatu zen: herri-Nazioa bezala mistifikatuta, bere mesianismo politikoarekin, bazterketa, konplizitatea, dominazioa eta kontra-egitearen aztarnak ezabatuta (Martín-Barbero 1993).

Anarkistek eta marxistek erromantikoen kulturalismoarekin apurtu zuten: herria eta popularra kontzeptua politizatu egin zituzten, historiaren aztarnak eta zapalkuntza eta borrokaren seinaleak nabarmenduz.

Desde diferentes perspectivas y con distinto signo ideológico, los tres pensadores de la "sospecha" (Freud, Marx y Nietzsche) denunciarán cómo tras la formación del sujeto moderno se esconde también un proceso histórico de inusitada violencia y barbarie, de incorporación e interiorización de unas estructuras sociales, unas pautas culturales y unos universos de sentido alienantes de extrema crueldad represiva. Estos tres autores, a su vez, alimentarán (en ocasiones de forma muy contradictoria) la sensibilidad y la protesta tout court del modernismo cultural y de las vanguardias artísticas.

(Casanovas 2012, 47) 
Izan ere, plano kulturalean, haustura sakonagoa, erradikalagoa, totala izango zen. 1848tik aurrera gorpuzten hasia zen, erromantikoen mistifikazioa zaila zen mantentzen:

Los pactos de la burguesía con la aristocracia después de las revoluciones de 1848 expresarán perfectamente su temor a seguir jugando con ideas revolucionarias ante la aparición en la escena histórica de unas fuerzas populares cada vez más organizadas y conscientes de su propia fuerza revolucionaria y de sus intereses antagónicos respecto a la burguesía. En esta contradicción quedarán atrapados muchos artistas e intelectuales que reaccionarán contra su origen de clase, rompiendo con el conservadurismo social y el pragmatismo burgueses.

(Casanovas 2012, 36)

I. Mundu Gerran burgesiak, klase bezala, bere hobengabetasuna galdu zuen behin betiko. Ilustrazioaren amets eta promesa aurrerakoiak, erromantikoen epika heroikoa, herritarra eta nazionalista; horiek guztiak hondoratu ziren Frantziako trintxera erraldoi batean. Mende hasierako abanguardiek, Dadák, konstruktibismoak eta Futurismoak, mistifikazio guztiekin apurtu zuten, kulturalak, nazionalak, esentzialismoa... Artelan totalak totalitarismoa ekar dezake; motxilan Goetheren liburu bat daramazula trintxera batean hiltzeko baino ez du balio, esango zuten dadaistek. Kultura oldartu, Artea suntsitu.

Duchamp: gustu ona da artearen areriorik handiena. Mugarik gabeko sormena, mozkortuta, eroa, espontaneoa, silaba eta hitzen musika absurdoa, dena desegin eta berregin gauero Zuricheko Cabaret Voltairen: Dadá. Fartsa erraldoi bat baino ez zen mendebaldeko kultura, Europan I. Gerra Mundialaren sarraskia odoltsua eragin zuena. Suntsitua izan behar zuen, zerotik hasteko, Artearen zerutar eskaileretan Faustoren ale bakar batek, hura editatzen jarraitu ahal izateko hil ziren milioi bat lagunek baino pisu gehiago zeukan eta (Marcus 2005).

Después de una época de locura y desgarramiento, gobernada por bandidos que habían destruido Europa, el arte debía sumarse a la higiénica labor de desmantelamiento, debía echar por tierra lo que quedaba de una civilización sangrienta, y despojar al individuo del revestimiento occidental que había hecho de él un cómplice de 
la barbarie. (...) El arte no tenía ningún valor, la vida era mucho más interesante.

(Granés 2011, 43)

Errusiar konstruktibistek 1917ko iraultzan bizi zuten gizarte eta izaki berri baten sortzeko aukera. Han hedatu zituzten beraien proposamenak eta esperimentazioa Leninek bizirik iraun zuen bitartean.

Museoak, liburutegiak eta era guztietako akademiak suntsitu. Futuristek garapen teknologiko berrietan ikusi zuten gizarte berri baten utopia: makinak, mugimendua, abiadura. Eta haietako batzuentzat, guda izan zitekeen kultura "birsortzeko" bidea. Luigi Russolok 1913an musikagintzan aplikatu zituen ideia futuristak, L'arte dei Rumori testu ospetsuan, hotsen artea:

La vida antigua fue toda silencio. En el siglo diecinueve, con la invención de las máquinas, nació el Ruido. Hoy, el Ruido triunfa y domina soberano sobre la sensibilidad de los hombres. (...) El arte musical buscó y obtuvo en primer lugar la pureza y la dulzura del sonido, luego amalgamó sonidos diferentes, preocupándose sin embargo de acariciar el oído con suaves armonías. Hoy el arte musical, complicándose paulatinamente, persigue amalgamar los sonidos más disonantes, más extraños y más ásperos para el oído. Nos acercamos así cada vez más al sonido-ruido. Esta evolución de la música es paralela al multiplicarse de las máquinas, que colaboran por todas partes con el hombre. (...) Nosotros los futuristas hemos amado todos profundamente las armonías de los grandes maestros y hemos gozado con ellas. Beethoven $y$ Wagner nos han trastornado los nervios y el corazón durante muchos años. Ahora estamos saciados de ellas y disfrutamos mucho más combinando idealmente los ruidos de tren, de motores de explosión, de carrozas y de muchedumbres vociferantes, que volviendo a escuchar, por ejemplo, la "Heróica" o la "Pastoral". (...) Estamos pues seguros de que escogiendo, coordinando y dominando todos los ruidos, enriqueceremos a los hombres con una nueva voluptuosidad insospechada. Aunque la característica del ruido sea la de remitirnos brutalmente a la vida, el Arte de los ruidos no debe limitarse a una reproducción imitativa. Esta hallará su mayor facultad de emoción en el goce acústico en sí mismo, que la inspiración del artista sabrá extraer de los ruidos combinados. ${ }^{3}$ 
1937. John Cagek Construction In Metal konposatzeari ekin zion: gameland-ak, metalezko xaflak, balazta diskoak... 1948an Pierre Shaefferrek musika konkretua sortu zuen, eta berehala Pierre Henryk bat egin zuen berarekin, gehi beste batzuek gerorago: Luc Ferrari, François Bernard Mâche edo Bernard Parmegiani. Ez dute pianoa jotzen, puskatu baino; orrazi edo lima bat, xaflak, malgukiak, industriaren hondakinak. 60ko hamarkada: La Monte Young, Fluxus taldean, John Cale eta Velvet Underground... Zarata, musika jarraitua, errepikapena (Kyrou 2006).

Eta beraien aztarnak. Krautrock mugimendua Alemanian 60ko hamarkadan, Karlheinz Stockhausen musikagilearen seme-alabak: Can, Neu!, Faust, Tangerine Dream edo Kraftwerk. Rocka eta tresna elektronikoak, gehi soinu ekialdetar eta afrikarrak; makinen soinuak, roboten dantzak. Ingalaterran 70ko hamarkadan, Throbbing Gristle edota Cabaret Voltaire: "industrial music for industrial people".

Eta hamarkada amaieran, eztanda: punka. Ingalaterran, Euskal Herrian... Zarata sinplea, hitz zorrotzak; kapitalismoaren krisia, ukazioa eta haustura, baimena ezta barkamena eskatu barik; basatia, bizkorra, zuzena, probokatzailea, berehalakoa, espontaneoa, existentziala; audientzia eta musikarien mugak deuseztatuz, Do It Yourself!

Más que bolsas de basuras o camisetas rotas, los punks eran una mórbida erupción de Adorno y de ella provenía el diseño de los dibujos con que decoraban sus cuerpos. Igual que los cadáveres disecados de Adorno, más conscientemente preparados de lo que él había podido imaginar, estallaban con pruebas de vitalidad, es decir, decían lo que querían decir.

Y al hacerlo daban la vuelta a la visión que de la vida moderna había tenido Adorno: éste no se había imaginado que los cadáveres pudieran saber lo que querían decir.

(Marcus 2005, 84)

II. Mundu Guda osteko langile klaseko subkultura musikalek - Teddy Boy, Mod, Rocker, Skinhead edo punka - kontraesan estrukturalak adieraziko zituzten. Artikulazio bikoitza burutuko zuten: gurasoen langile klaseko kultura, alde batetik, eta masa kultura, bestetik. Horrela, kontraesanak "magikoki" konponduko ziren plano sinbolikoan. Kultura burgesaren aurreko erresistentzia sinbolikoa izango zen, gazteei eguneroko espazioak eraikitzen lagunduz, non 
beraien autonomia, autoestimua, eta subjektibitatea garatzeko aukera ematen zen (Hall eta Jefferson 2006, Hebdige 2004).

Itsasoaren bestaldean, sound system izpiritua, Kingstonetik maletetan ekarrita, Bronxeko baztertutako kaletan mutazioa izango zuen: hip-hopa. Disko musikaren urte eroak ere baziren New Yorken: hedonismoa, gozamena eta ospe nahia.

Huron lakuaren ertz kutsatuetan, Detroiten, automobil-industriaren zaraten artean, Juan Atkins, Kevin Sauderson eta Derrick May hirukote beltzaren eskutik soinu elektroniko berriak sortu ziren 80ko hamarkadaren erdialdean: tekno musika. Bigarren belaunaldi batek emango zion bultzakada: Carl Craig, Kenny Larkin, Richie Hawtin. Edota Mad Mike eta Jeff Mills Underground Resistance kolektiboan: zaratak, sisteman interferentziak sortzeko. Aldi berean eta harremanetan, Chicagon, disko musikaren hondarretatik house musika jaio zen, minimal iraultza erritmo-kaxa batean. Europatik zabalduko zen 80ko hamarkadaren amaieran rave eta free party festetan, hondakin industrialei une bateko bizitza emanez. Gune pirata batzuetan teknoa muturrera erradikalizatu zen, bere erritmo eta zaraten eskeletora: hardcore. Ondoren, Dj batzuek hiphopeko breakbeats efektuak sartu zituzten hardcorean: breakbeat erritmoa jaio zen. 1991 eta 1994 bitartean breakbeat erritmoa jungle bihurtu zen, eta geroago, drum'n bass (Kyrou 2006).

Klub kulturaren garapenarekin batera, Sarah Thorntonek (1995) determinazio estrukturalak - klasekoa - gainditzeko bidea ikusi zuen. Kultura jasoari eta Bourdieuren kapital kulturalari buelta emanez, kapital subkultural delakoak, estiloren bitartez, gazteei beraien gurasoen klase ezaugarrietatik ihes egiteko aukera emango zien, classlessness bezalako zerbait bilatuz. Kapital subkulturalak cool estatusa izango zen, berezko underground gustuak legitimatzean metatzen dena, mainstream gustuetatik diferentziatuz. Medioen eragina nabarmentzen da mekanismo hauetan (Muggleton 2010).

Erreprodukzio teknikoen garaiak artelanen auraren heriotza dakar, esan zuen Adornok (Adorno eta Horkheimer 1994) ezkortasun kultural batean murgilduta; jazz gorrotatzen zuen, "probablemente le habrían entrado náuseas la primera vez que oyó a Elvis Presley, y no hay duda de que habría considerado a los Sex Pistols como un retorno a la Kristallnacht si no hubiese tenido la suerte de morir en 1969" (Marcus 2005, 84). Benjaminek, aldiz, beste perspektiba bat apuntatu zuen, pertzepzio moduak, sensorium delakoan Modernitatearekin batera ematen diren aldaketak: "Dentro de grandes espacios históricos 
de tiempo se modifican, junto con toda la existencia de las colectividades humanas, el modo y manera de su percepción sensorial", por lo que se trata entonces de "poner de manifiesto las transformaciones sociales que hallaron expresión en esos cambios de sensibilidad" (Benjamin 1989, 23-24).

Para Benjamin la "experiencia" es ante todo una cuestión de "tradición", es decir, aquello que permite restituir en el sensorium humano (tanto en el ámbito personal como en el colectivo) una "contra-historia" personal y colectiva dotada de sentido frente a las vivencias aisladas y atomizadas del presente capitalista.

(Casanovas 2012, 23)

Izan ere, artelan totalaren auraren heriotzarekin batera datorren sentsibilitate berria gerturatzekoarena da, artelanak erabili eta gozatzekoarena. Sentsibilitate berriak berdintasun eskaerak dakartza, bereizkuntza eta pribilegioen abolizioa. Eta dispertsioa, anizkun irudia eta collagea dira pertzepzio modu berrien dispositiboak. Sensorium berri honetan beste osagai garrantzitsu bat ere badago, Baudelairetik datorrena: jende artean, jendetzan, egotearen gozamena (Martin-Barbero 1993).

Zaratak tonalismoaren kontra, musika jasoaren kontra. Autonomia kulturala, musika eta kulturaren demokratizazioa; egunerako bizitzaren zarata-soinuak, zuk zeuk eginda. Zaratak, abiadura. Homologiarako parada: Kapitalaren errotazio abiaduraren bizkortzearekin batera, denbora sozialaren eta, hortaz, musikaren erritmoa ere azeleratu egin da. Musika industrialak, punkak eta elektronikak beraien garaiko zaratak (eta abiadura) hartzen dute oinarri.

Orain zarata da esentzia (edo sasi-esentzia; esentzia ez sendoa, ez totala, zatikatua). Baina aldi berean zarata hauek soinu izan nahi dute, komunikatu nahi dute, beraien garaiko inkomunikazioa bada ere komunikatzen dutena. Eguneroko bizitzaren soinuak, berezkotasuna eta inprobisazioa. Gizarte industrialaren zarata-soinuak. Utopia eta distopia teknologikoak. Nazka eta amorruaren garrasia, edo ihesaldiak. Edota, subkulturen kasuan, langile klaseko gazteen kontraesan estrukturalen adierazpena. Zaratak soinua dakar.

\section{ZARATA TOTALA?}

3. premisa: Kapitalismo bizkortua eta bere logika kultural postmodernoak, zatiketa, erabili eta botatzearena, produktu kulturalen hustuketa sustatzen 
dute. Hortaz, musikaren esanahi soziala eta sentsibilitate sentsoriala aldatzen dira.

1970ko hamarkadako krisia eta gero - punk eztanda eragin zuena -, hurrengo hamarkadetan garatzen den kapitalismoaren fase berriak enpresa fordistak zatikatu egin zituen, azpikontratazioen bidez, irabazte-tasa handituz eta indar sindikala ahulduz aldi berean. Posfordismo eta Estatu Schumpeteriar Konpetitiboaren eredua inposatuko zen (Jessop 2008). Merkatu eta produktu uniformeak, masakoak, saturatuta agertu ziren, eta globalki merkatu segmentatuak eta produktu pertsonalizatuak garatuko ziren aurrerantzean. Produktuen zikloak ere azkartuko ziren, gero eta laburragoak izanik; azelerazio eta zatikatze prozesuetan sakonduz.

Kapitalismoaren fase berri honen logika kulturala postmodernitatea izango da (Jameson 1995); azelerazioa eta zatiketa ere dauka oinarri. Logika honek dakarren sentzibilitatea abangoardiek (dadá edo situazionismoa) edo punkak berak, eta zer esanik ez hip-hopak edo elektronikak, garatu zuten: brikolagea, elementu diferenteen konbinazioa. Izan ere, postmodernitateak kritika kulturalek planteatutako hainbat idei, imaginario eta sentsibilitate jasotzen ditu. Bat izan ezik: abangoardiek merkantilizazio prozesuei egindako kritika, eta mugimendu kulturalen praxi popularra eta auto-eratua.

Izan ere, fase neoliberal honetan logika komertzialaren barneratze prozesuak areagotu egiten dira kulturgintzako estadio guztietan, kultur eremuen independentzia eta erdi-autonomia kolokan jarriz (Bourdieu 2011). Kapitalismo globalaren logika nagusitzen da: erosi, erabili, eta botatzearena. Kapitalaren errotazioaren azelerazioak, gehi diskurtso postmodernoaren erlatibismoak, dakarten sentsibilitateak ( du.

Garraiobideek eta informazio eta komunikazio teknologiek izan duten garapenak prozesu hauek guztiak bultzatzen lagundu du. Musikagintzan eragin berezia izaten ari dira XXI. mendean. Izan ere, Internetak sakon aldatu ditu musika eskuratzeko modu sozialak, indibidualagoak bihurtuz, harreman sozial eta sare pertsonalik behar ez dutenak. Hau da, lehen musika eskuratze prozesuan harreman pertsonalak sortzen ziren: disko dendan, tabernetan, diskoak trukatu edo grabatzen zituzten lagunen artean... Askotan, musikaren inguruko talde sozialak sortuz, subkulturak edo neo-tribuak. Egungo teknologia 
berrien bitartez, egia da, elkartrukea egon badago, baina ez dauka harreman pertsonal zuzenek zeukaten intentsitate ezta dimentsio afektiborik.

Beste garapen teknologiko batzuek zatiketa prozesuan eragin handia izan dute: spotify eta mp3 formatua dira egungo entzute modu nagusiak, batez ere gazteen artean (Andrés 2013, Fouce 2009). Horrela, diskoak zeukan narratiba eta diskurtsoa zatikatu egiten dira. Diskoak berak zituen beste elementu batzuk ere galtzen dira: portada, argazkiak, testua... Horiek guztiak musikatik haratago joatea ahalbideratzen zuten, taldea eta bere testuinguruaren berri emanez. Horren ordez, abestia da oinarrizko zelula musikala orain. Pasarte musikal isolatu eta heterogeneoak topatzen ditugu; Playlist batean kateatuak, edo Dj batek birrinduta.

Abesti solteak. Eta entzutetsuak. Internet eskuragarri daukagun artxibo erraldoi bat bada ere, ematen du gero eta gehiago entzuten dela musika bera, ezaguna dena (Álvarez Monzoncillo eta Calvi 2015). Hau da, kanta klasikoak, edo beraien berregiteak (Reynolds 2013). Edo medioek bultzatzen dutenak (Álvarez Monzoncillo eta Calvi 2015). Elkarrekin kantatu daitezkeenak, jaietan edo jaialdietan (Del Amo 2014).

Ultrakonexioaren garaian, musika deskonektatuta agertzen zaigu: kanta solteak, beraien testuinguru orokorretik erauziak. Kapitalismoaren logikaz blai: hartu eta nahasi, erabili eta bota. Azelerazioa eta zatiketa honek, musikaren balio galera dakar, zarata totala bihurtu ei da? Dena den, aldi berean erabiltzeko modu hauek, eta abesti entzutetsuen garrantziak, konpartitzeko, sentsibilitate berritu baten berri ematen digu.

Soinu totalak bere garaiko esentzia antzematen saiatu zen, gizarte aske eta berri baten amets heroikoa, iraultza askatzailea, aurrerapen lineala. Horren ostean, eta horren kontra ere bai, zaratek soinu totalaren amets gaiztoak salatu, eta eguneroko bizitzaren eta gizarte industrialaren soinuak hartu zituzten, artea eta bizitza uztartuz. Zarata-soinuak heroikoak ere baziren askotan, sentsibilitate berri bat antzematen zutenak, kulturaren demokratizazioarena. Izan ere, kontraesan estrukturalak adierazten zituzten, langile klaseko subkulturak kasu. Edo zarata-soinuak determinazio estrukturalak - klasekoa - gainditzeko bidea izan zitezkeen, kultura jasoari buelta emanez eta kapital subkulturala garatuz.

Zarata totalaren gaian ez dago heroismorik, ez dago eskaerarik. Musika erabili eta botatzeko zerbait da, kapitalismoaren logikaz blai. Benjaminek seinalatu zituen pertzepzio modu berrien dispositiboek - dispertsioa, anizkun irudia 
eta collagea - jarraitzen dute izaten, muturrera eramanda, azeleratuagoak eta zatikatuagoak. Baina garaiko sentsibilitateak Baudelaire eta Benjaminek nabarmendu zuten beste elementu bat mantentzen du: jende artean egotearen gozamena. Hori da egungo sensorium honek dakarren ezaugarririk nabarmena: soinua, zarata bihurtuta, sozialidaderako bide bat da batez ere. Abesti soltez eta deskonektatuez osatutako zarataren artean, kanta famatuek, ezagunek, (bir)konektatzeko parada ematen dute, elkarrekin abesteko, elkarrekin egoteko.

\section{Erreferentziak}

Adorno, Theodor W. \& Max Horkheimer. (1944) 1994. Dialéctica de la ilustración. Traducción de Juan José Sánchez. Madrid: Trotta

Álvarez Monzoncillo, José María \& Juan Carlos Calvi. 2015. "Music consumption in Spain: From analogue to digital in the shaping of music. International Journal of Music Business Research 4(2): 27-46

Andrés Cabello, Sergio (2013). "Del cassette al spotify: Universitarios, hábitos e identidades musicales". Ikerlana [estudio] Univ. de La Rioja, www.unirioja.es/apnoticias/servlet/ Archivo?C BINARIO $=4626$

Benjamin, Walter. (1936) 1989. "La obra de arte en la época de la reproductibilidad técnica”. En: Discursos interrumpidos I. Prólogo, traducción y notas de Jesús Aguirre. Buenos Aires: Taurus

Bergeron, Louis, François Furet \& Reinhart Koselleck. 1969. La época de las revoluciones europeas, 1780-1848. Traductor, Francisco Pérez Gutiérrez. Madrid: Siglo XXI

Bourdieu, Pierre. 1999. La distinción: criterios y bases sociales del gusto. Traducción de Ma. del Carmen Ruiz de Elvira. Madrid: Taurus

- 2001. Contrafuegos 2. Por un movimiento social europeo. Traducción de Joaquín Jordá. Barcelona: Anagrama

Casanovas, Marc. 2012. Organizar el rechazo: Vanguardias culturales y política revolucionaria. Madrid: Izquierda Anticapitalista

Del Amo Castro, Ion Andoni. 2014. "Party \& Borroka. Jóvenes, música(s) y conflicto(s) en Euskal Herria: Transformaciones identitarias a comienzos del siglo XXI". EHUko doktoretza tesia [Tesis Univ. del País Vasco]

Fouce Rodríguez, Héctor. 2009. Prácticas emergentes y nuevas tecnologías: El caso de la música digital en España. Madrid: Fundación Alternativas

García Canclini, Néstor. 2001. Culturas híbridas: Estrategias para entrar y salir de la modernidad. Barcelona: Paidós

Granés Maya, Carlos. 2011. El puño invisible: Arte, revolución y un siglo de cambios culturales. Madrid: Santillana

Hall, Stuart \& Tony Jefferson, eds. 2006. Resistance Through Rituals: Youth Subcultures in Postwar Britain. London: Routledge 
Harvey, David. 1998. La condición de la posmodernidad: Investigación sobre los orígenes del cambio cultural. Traducción, Martha Eguía. Buenos Aires: Amorrortu

Hebdige, Dick. 2004. Subcultura: El significado del estilo. Traducción de Carles Roche. Barcelona: Paidós

Hobsbawm, Eric. 2003. Historia del Siglo XX, 1914-1991. Traducción castellana de Juan Faci, Jordi Ainaud y Carme Castells. Barcelona: Crítica

Jameson, Fredic. 1995. El postmodernismo o la lógica cultural del capitalismo tardío. Traducido por Esther Pérez, Christian Ferrer y Sonia Mazzco. Barcelona: Paidós

Jessop, Robert. 2008. El futuro del estado capitalista. Traducción de Antonio de Cabo y Aniza García. Madrid: Catarata

Kyrou, Ariel. 2006. Techno Rebelde: Un siglo de músicas electrónicas. Traducción, Manuel Martínez Forega. Madrid: Traficantes de Sueños

Marcus, Greil. 2005. Rastros de Carmín: Una historia secreta del siglo XX. Traducción de Damián Alou. Barcelona: Anagrama

Martin Saura, Leónidas. 2006. Introducción a la ed. española de Techno Rebelde: Un siglo de músicas electrónicas Ariel Kyrou, 13-18. Madrid: Traficantes de Sueños

Martín-Barbero, Jesús. 1993. De los medios a las mediaciones: Comunicación, cultura y hegemonía. México: Gustavo Gili

Mattin [Mattin Artiach Oráa] \& Anthony lles,e ds. 2010. Noise \& Capitalism [Ruido y Capitalismo]. Colaboradores, Ray Brassier et al. Donostia: Arteleku Audiolab. Versión en castellano: www.mattin.org/ruido capitalismo.pdf

Morey Farré, Miguel. 2015. Foucault y Derrida: Pensamiento francés contemporáneo. Valencia: Batiscafo

Muggleton, David. 2010. "From classlessness to clubculture: A geneaology of postwar British youth cultural analysis". Young 12(2): 205-19

Negus, Keith. 1996. Popular Music in Theory: An Introduction. Cambridge, UK: Polity

Reynolds, Simon. 2013. Retromanía: La adicción del pop a su propio pasado. Traducción Teresa Arijón. Buenos Aires: Caja Negra

Thornton, Sarah. 1995. Club Cultures: Music, Media and Subcultural Capital. Cambridge, UK: Polity

\section{Oharrak}

1 Sinfonia hau link honetan entzun daiteke: https://www.youtube.com/watch?v=nbGV-MVfgec

2 Datu hauek Wipediatik hartu ditugu (Sarbidea 2015/11/27): https:/les.wikipedia.org/wiki/Sinfon \%C3\%ADa n.\%C2\%BA 3 \%28Beethoven $\% 29$

3 http://www.uclm.es/artesonoro/elarteruido.html, sarbidea 2015/11/26. 